\title{
UPAYA MENINGKATKAN MINAT NASABAH MENABUNG PADA PT. BANK PERKREDITAN RAKYAT JORONG KAMPUNG TANGAH PARIAMAN
}

\author{
Novia, Ratna Widayati \\ Akademi Keuangan dan Perbankan "Pembangunan" (AKBP) Padang \\ novia167828@gmail.com
}

\begin{abstract}
The purpose of this research was conducted to find out the efforts made Of PT. Bank Rakyat Jorong Kampung Tangah Pariaman in increasing customer interest in saving. In analyzing the data, the authors use a qualitative data analysis as a research method that is explained in the descriptive. In this research it can be concluded the efforts made Of PT. Bank Rakyat Jorong Kampung Tangah Pariaman is doing a Promotion with the mounting board bilboard, share calendars, and disseminating brochures to clients and prospective clients with the goal of keeping potential borrowers to know the products and services that exist, then rely on patterns of marketing namely savings services by using bajapuik which is getting positive response from customers, as evidenced by the presence of bajapuik increased savings customer saving increasing annually.
\end{abstract}

Keywords :Bank,Savings,Marketing.

\section{PENDAHULUAN}

Bank adalah suatu lembaga keuangan yang saat ini berperan sangat penting bagi perkembangan ekonomi nasional, melalui penerapan dan fungsinya bank bertugas sebagai lembaga intermediasi antara penyimpan dan para pengguna dana melalui pemanfaatan fasilitas berupa produk maupun jasa-jasa perbankan lainnya(Praevillia, 2017)

Menurut Afriyeni, (2009) Bank berperan sebagai lembaga keuangan yang melakukan penghimpunan dana dari masyarakat dan selanjutnya menyalurkan kembali dalam bentuk kredit. Bank dapat memberikan bermacam-macam jasa pembiayaan. Bank juga dapat melayani kebutuhan masyarakat dan dunia usaha pengguna jasa kredit untuk meningkatkan kualitas kehidupan masyarakat.

Sedangkan menurut Abdullah, (2009) Bank ialah sebuah lembaga intermediasi keuangan yang biasanya didirikan dengan tujuan untuk menerima simpanan uang, meminjamkan uang, dan menerbitkan promes atau yang dikenal sebagai banknote. Bank adalah badan usaha yang melakukan penghimpunan dana dari masayarakat dalam bentuk simpanan dan menyalurkan kembali dalam bentuk kredit atau bentuk-bentuk lainnya yang bertujuan untuk meningkatkan taraf hidup masyarakat banyak.

Menurut pasal 1 ayat 2 Undang-UndangNo.10 Tahun 1998 tentang perubahan atas Undang-Undang No.7 Tahun 1992 tentang perbankan, Bank merupakan badan usaha yang kegiatannya menghimpun dana dari masyarakat 
dalam bentuk simpanan dan menyalurkan kembali dalam bentuk kredit dan bentuk lainnya dalam rangka meningkatkan taraf hidup masyarakat banyak.

Seiring dengan perkembangan perbankan dan minat yang banyak dari masyarakat, banyak bank yang mulai bermunculan, salah satunya PT. Bank Perkreditan Rakyat Jorong Kampung Tangah Pariaman yang merupakan salah satu bank yang sangat berperan penting dalam pertumbuhan ekonomi di kalangan masyarakat menengah kebawah khususnya di Pariaman.

Bank Perkreditan Rakyat merupakan salah satu jenis bank yang dikenal melayani golongan pengusaha mikro, kecil dan menengah dengan lokasi yang pada umumnya dekat dengan tempat yang membutuhkan.(Hary, 2014)

Perkembangan bank semakin pesat yang merupakan dampak dari pertumbuhan ekonomi sehingga terjadilah persaingan antar bank yang sangat ketat didalam dunia perbankan. Setiap bank menawarkan berbagai produk sebagai fasilitas dan kemudahan bertransaksi yang bertujuan untuk menarik minat masyarakat banyak untuk menggunakan jasa yang ditawarkan oleh bank tersebut. Masyarakat dapat menentukan produk dan jasa bank mana yang akan di gunakan sesuai keinginan dan kebutuhan masyarakat itu sendiri, dan salah satu produk yang ditawarkan oleh bank adalah tabungan yaitu simpanan pada bank yang penarikannya hanya dapat dilakukan menurut syarat tertentu yang telah disepakati antara kedua belah pihak.

Kepuasan nasabah dapat ditentukan dengan kualitas produk yang ditawarkan dan layanan yang diberikan, sehingga jaminan dari kualitas produk menjadi hal utama yang paling diprioritas bagi pihak bank. Kualitas dari produk yang ditawarkan bank didapatkan dengan cara mencapai keinginan dan harapan nasabah, dengan meningkatkan nilai produk dan pelayanan dikatakan mempunyai nilai yang tinggi dimata nasabah apabila bank tersebut mampu memberikan kualitas, manfaat dan pengorbanan seminimal mungkin(Trisnadi, 2013). Oleh karena itu pihak bank harus meningkatkan kualitas dengan melakukan upayaupaya agar calon nasabah berminat untuk menabung pada bank tersebut.

Berdasarkan uraian diatas, maka penulis tertarik untuk melakukan penelitian dan membahasnya dalam tugas akhir yang berjudul "Upaya Meningkatkan Minat Nasabah Menabung Pada PT. Bank Perkreditan Rakyat Jorong Kampung Tangah Pariaman".

\section{METODE PENELITIAN}

Dalam menganalisa data, penulis menggunakan analisis data kualitatif sebagai metode penelitian yang menjelaskan secara deskriptif mengenai bagaimana upaya meningkatkan minat nasabah menabung pada PT. Bank Perkreditan Rakyat Jorong Kampung Tangah Pariaman.

\section{HASIL DAN PEMBAHASAN}

Dalam upaya meningkatkan minat nasabah menabung PT. BPR-JKT Pariaman melakukan langkah-langkah sebagai berikut :

\section{Melakukan Pemasaran}

Pemasaran merupakan suatu kegiatan yang mengatur seluruh sistem yang berhubungan langsung dengan tujuan serta merencanakan dan menetapkan 
harga, lokasi, sampai dengan mempromosikan dan mendistribusikan barang dan jasa yang dapat memuaskan kebutuhan pembeli secara nyata(Hapsari \& Madiawati, 2015)

a. Produk

PT. BPR-JKT Pariaman memiliki tiga jenis tabungan yaitu :

1) Tan (Tabungan Anak Nagari) Bunga 4.00\%/Tahun.

2) Tamasda (Tabungan Masyarakat Daerah) Bunga 4.00\%/Tahun.

3) Tabsis (Tabungan Siswa) Bunga 3.50\%/Tahun.

Untuk menarik minat nasabah menabung PT. BPR-JKT Pariaman melakukan strategi yang sesuai dengan keinginan dan kebutuhan nasabah.Strategi andalan PT. BPR-JKT Pariaman adalah penjemputan tabungan yaitu ketika ada nasabah yang ingin menabung, nasabah tersebut tidak perlu susah payah pergi ke bank karena pihak bank melakukan pelayanan penjemputan langsung kerumahnasabah yang ingin menabung. Strategi ini dinamakan Tabungan Bajapuik.

b. Harga

PT. BPR-JKT Pariaman mengupayakan penetapan harga yang rendah untuk simpanan dana pihak ketiga (DPK) dan menghapuskan biaya administrasi.

c. Lokasi

PT. BPR-JKT Pariaman berlokasi di jl. Adienegoro pasar Lb. Buaya Padang dan itu merupakan tempat yang sangat strategis, dimana di dekat lokasi usaha terdapat pasar dan pemukiman padat penduduk. Dengan lokasi yang sangat strategis tersebut diharapkan dapat menambah jumlah nasabah.

d. Promosi

Promosi adalah suatu bentuk komunikasi yang dilakukan perusahaan dalam menjalankan usaha, serta merupakan kegiatan dari pemasaran yang bertujuan untuk menyebarkan informasi, mempengaruhi, membujuk atau meningkatkan pasar sasaran atas perusahaan dan produknya agar masyarakat tertarik dan bersedia menerima, membeli serta loyal pada produk yang ditawarkan perusahaan yang bersangkutan.(Selang, A.D, 2007)

Promosi merupakan cara ampuh untuk memperkenalkan produk yang dimiliki PT. BPR-JKT Pariaman kepada masyarakat banyak, Promosi ini dilakukan untuk menarik minat nasabah agar jumlah nasabah semakin meningkat pada bank tersebut. Bentuk promosi yangdilakukan yaitu turun langsung kelapangan dengan mempromosikan produk-produk yang ada.

Bentuk Promosi yang dilakukan PT. BPR-JKT Pariaman.

1) Periklanan (Adversting)

Iklan adalah salah satu sarana promosi yang digunakan oleh PT. BPR-JKT Pariaman yang bertujuan menginformasikan segala jenis produk dan jasa yang dihasilkan oleh bank. Informasi yang dimaksud seperti manfaat produk, harga, keunggulan dan keuntungan-keuntungan produk yang didapat. Tujuan promosi lewat iklan adalah berusaha untuk menarik dan mempengaruhi calon nasabah.

Penggunaan promosi dengan iklan yang dilakukan PT. BPR-JKT Pariaman: 
a) Pemasangan billboard (Papan nama) di tempat strategis seperti di depan kantor.

b) Pencetakan brosur baik yang disebarkan di setiap kantor pusat dan cabang. Penyebaran brosur ini diharapkan dapat menarik minat calon nasabah.

c) Membagikan Kalender

PT. BPR-JKT Pariaman membagikan kalender kepada nasabah dan calon nasabah yang berisikan foto kegiatan yang dilakukan di PT. BPR-JKT Pariaman, serta produk dan jasa yang ditawarkan.Kalender ini dibagikan langsung oleh karyawan saat penjemputan tabungan kerumah nasabah.

2) Promosi Penjualan (Sales Promotion)

Tujuan promosi penjualan ini adalah untuk meningkatkanjumlah penjualan atau untuk meningkatkan jumlah nasabah. Promosi ini diharapkan dapat membuat nasabah tertarik untuk membeli produk dan jasa yang ditawarkan PT. BPR-JKT Pariaman. Promosi penjualan dilakukan melalui pemberian cendra mata, hadiah atau kenang-kenangan lainnya kepada nasabah yang loyal.

3) Mengadakan Acara Tahunan

Acara tahunan yang dimaksud adalah untuk menyambut hari-hari besar seperti ulang tahun PT. BPR-JKT Pariaman dan hari kemerdekaan RI. Acara yang diselenggarakan setiap tahunnya dengan membagikan hadiah kepada nasabah yang beruntung.

4) Melakukan Pelayanan Prima

Menurut Fitria, (2012) Layanan merupakan suatu aktivitas dan manfaat yang dapat diberikan suatu pihak kepada pihak lainnya yang pada dasarnya tidak memiliki wujud. Layanan juga dapat disebut sebagai tindakan membantu, menolong, memudahkan, menyenangkan, dan memberi manfaat bagi orang lain.

Pelayanan prima yang dilakukan PT. BPR-JKTPariaman merupakan salah satu kewajiban yang dilakukan oleh seluruh staf dan karyawan dalam melayani nasabah sebaik-baiknya. Sehingga nasabah tersebut merasa puas dengan pelayanan yang ada pada PT. BPR-JKT Pariaman. Salah satu contoh pelayanan yang dilakukan yaitu ketika nasabah memasuki bank, securityakan menyapa dan bertanya, lalu security tersebut akan menunjukan ketempat yang nasabah butuhkan, seperti ke teller bank, selanjutnya pihak teller akan tersenyum dan menyapa nasabah dan langsung memberikan pelayanan, setelah pelayanan selesai teller akan bertanya kembali, apakah ada lagi yang dibutuhkan nasabah tersebut.

Tabungan Bajapuik merupakan pelayanan yang diberikan PT. BPR-JKT Pariaman kepada nasabahnya dengan tujuan memudahkan nasabah untuk menabung. Tabungan Bajapuik adalah proses penjemputan tabungan yang dilakukan secara kolektif ke alamat atau ketempat usaha nasabah itu sendiri. Tabungan dijemput atas kemauan nasabah dan penjemputan bisa dilakukan setiap hari ataupun sekali 
seminggu tergantung kesepakatan antara si penabung dengan pihak bank.Nasabah harus mengonfirmasi pada saat pembuatan rekening, ingin dijemput dimana dan seminggu berapa kali penjemputan.Tabungan yang biasa dijemput adalah tabungan jenis Tabungan Anak Nagari (TAN), Tabungan Masyarakat Daerah (TAMASDA) dan Tabungan Siswa (TABSIS).

Dari upaya yang dilakukan PT. BPR-JKT Pariaman dengan pelayanan tabungan bajapuik, telah terjadinya peningkatan jumlah nasabah yang dapat dilihat dari tabel berikut :

Tabel

Jumlah Nasabah Tabungan PT. Bank Perkreditan Rakyat Jorong Kampung Tangah Pariaman cabang Padang

Tahun 2015-2017

\begin{tabular}{|c|c|c|c|}
\hline Tahun & $\mathbf{2 0 1 5}$ & $\mathbf{2 0 1 6}$ & $\mathbf{2 0 1 7}$ \\
\hline $\begin{array}{c}\text { Jumlah } \\
\text { Nasabah }\end{array}$ & 2.346 & 3.110 & 3.920 \\
\hline
\end{tabular}

Sumber : PT. Bank Perkreditan Rakyat Jorong Kampung Tangah Pariaman cabang Padang

Tabel di atas menunjukan adanya peningkatan nasabah dari tahun ketahun. Pada tahun 2015 jumlah nasabah sebanyak 2.346 nasabah, pada tahun berikutnya yaitu tahun 2016 jumlah nasabah meningkat sebanyak 746 nasabah menjadi 3.110. Peningkatan nasabah paling banyak terjadi pada tahun 2017 yaitu sebanyak 810 nasabah menjadi 3.920.

Peningkatan jumlah nasabah ini terjadi karenaadanya upaya yang dilakukan PT. BPR-JKT Pariamandengan meningkatkan pelayanan melalui program tabungan bajapuik yang mendapatkan respon positif dari nasabah yang menabung, karena sebagian besar penabung berprofesi sebagai pedagang dan pengusaha UMKM yang kesehariannya sibuk sehingga sangat terbantu dengan adanya tabungan bajapuik.

\section{SIMPULAN}

Berdasarkan hasil penelitian pada bab sebelumnya dapat disimpulkan upaya yang dilakukan PT. BPR-JKT Pariaman dalam meningkatkan minat nasabah menabung sebagai berikut :

1. Melakukan Promosi dengan pemasangan papan bilboard, membagikan kalender, dan menyebarkan brosur kepada nasabah dan calon nasabah dengan tujuan agar calon nasabah mengetahui produk dan jasa yang ada pada PT. BPR-JKT Pariaman.

2. Mengandalkan pola pemasaran yaitu dengan menggunakan layanan tabungan bajapuik yang mendapatkan respon positif dari nasabah, terbukti dengan adanya tabungan bajapuik peningkatan nasabah menabung meningkat setiap tahunnya.

3. Mempertahankan loyalitas nasabah PT. BPR-JKT Pariaman dengan melakukan kegiatan berupa membagikan hadiah dan melakukan acara tahunan. 


\section{UCAPAN TERIMA KASIH}

Terimakasih penulis sampaikan kepada :

1. Kepada keluarga yang selalu memberikan dukungan.

2. Direktur AKBP beserta prodi AKBP yang telah memberikan kesempatan kepada penulis untuk melakukan penelitian ini.

3. Dosen Pembimbing tugas akhir yang telah memberikan arahan dan bimbingan hingga tugas akhir ini bisa terselesaikan.

4. Pimpinan PT. Bank Perkreditan Rakyat Jorong Kampung Tangah Pariaman.

5. Semua Pihak yang telah memberikan dukungan dan bantuannya dalam penyelesaian tugas akhir ini.

\section{DAFTAR PUSTAKA}

Abdullah, T. (2009). Lembaga Keuangan. Lembaga Keuangaan, 4, 1-43. https://doi.org/10.1016/j.nucengdes.2010.09.040

Afriyeni, A. (2009). Analisis Pengaruh Pemberian Kredit Terhadap Profitabilitas PT. Bank Pembangunan Daerah (BPD) Sumatera Barat. Jurnal KBP, 1(2), 95-107.

Fernandes, Y. D., \& Marlius, D. (2018). Peranan Customer Service Dalam Meningkatkan Pelayanan Kepada Nasabah Pada PT. Bank Pembangunan Daerah Sumatera Barat Cabang Utama Padang. https://doi.org/10.31227/osf.io/wrh3p

Fitria, H. (2012). Strategi Servis (Pelayanan Prima) Bank Syariah Terhadap Nasabah Non-Muslim (Studi Kasus Pada Bpr Syariah Amanah Ummah). Ekonomi Islam Al-Infaq, 3(1), 58-95.

Hapsari, V. N., \& Madiawati, P. N. (2015). Pengaruh Strategi Pasar Dan Bauran Pemasaran Terhadap Nilai Pelanggan Kareta Api Argo Parahyangan, 2(2), 2066-2073.

Hary, G. (2014). Analisis Faktor-Faktor Yang Mempengaruhi Kinerja Sistem Informasi Akuntansi Pada Bank Perkreditan Rakyat (BPR) Ditanjugpinang, $8(33), 44$.

Hidayati, R. R., \& Marlius, D. (2018). Aktivitas Promosi Dalam Meningkatkan Dana Pihak Ketiga Pada PT. Bank Perkreditan Rakyat (BPR) Batang Kapas Pesisir Selatan. https://doi.org/10.31227/osf.io/8dgqn

Marlius, D. (2016). Pengaruh Bauran Pemasaran Jasa Terhadap Minat Nasabah Dalam Menabung Pada Bank Nagari Cabang Muaralabuh. https://doi.org/10.31227/osf.io/vdqgx

Praevillia. (2017). Lex Crimen Vol. VI/No. 1/Jan-Feb/2017. Lex Crimen, VI(1), 
$115-122$.

Putra, A. M., \& Fernos, J. (2019). Pelaksanaan Pelayanan Prima Terhadap Kepercayaan Nasabah Di PT. Bank Perkreditan Rakyat Jorong Kampung Tangah Pariaman. https://doi.org/10.31227/osf.io/c3fy4

Safitri, R. N., \& Marlius, D. (2017). Penerapan E-Banking Dalam Meningkatkan Jasa Dan Layanan Perbankan Di PT. Bank Rakyat Indonesia Cabang Padang. https://doi.org/10.31227/osf.io/gkv8t

Selang, A.D, C. (2007). Bauran Pemasaran (Marketing Mix) Pengaruhnya Terhadap Loyalitas Konsumen Pada Fresh Mart Bahu Mall Manado, 1(3), 209-210.

Trisnadi, D. (2013). Pengaruh kualitas produk tabungan dan kualitas layanan terhadap minat menabung kembali di cimb niaga. Jurnal MIX, 6(3), 356368 .

Widayati, R. (2019). Upaya Meningkatkan Minat Untuk Menabung Pada PT. BPR Batang Kapas. https://doi.org/10.17605/OSF.IO/AEVW7

Widayati, R. (2019). Upaya Meningkatkan Nasabah Tabungan Melalui Tabungan Bajapuik Pada PT. Bank Perkreditan Rakyat (BPR) Jorong Kampuang Tangah (JKT) Pariaman. https://doi.org/10.17605/OSF.IO/36M48

Widayati, R. (2019). Aktivitas Pemasaran Produk Tabungan Pada PT. Bpr Rangkiang Denai Payakumbuh Barat. https://doi.org/10.17605/OSF.IO/S3UZM

Yuvendri, R., \& Susanto, R. (2019). Meningkatkan Mutu Pelayanan Dalam Usaha Menghimpun Dana Masyarakat (Tabungan) Pada PT. Bank Perkreditan Rakyat Prima Mulia Anugrah Cabang Padang. https://doi.org/10.31219/osf.io/6prcd 